Tema: $1^{\circ}$ Workshop de tratamentos de superfícies de ligas resistentes à corrosão

\title{
EFEITO DA NITRETAÇÃO A PLASMA EM BAIXA TEMPERATURA DO AÇO UNS S31803 SOBRE AS PROPRIEDADES TRIBOLÓGICAS MEDIDAS EM ENSAIO DE ESCLEROMETRIA LINEAR INSTRUMENTADA*
}

\author{
Luis Bernardo Varela Jiménez \\ Luis Armando Espitia Sanjuán ${ }^{1}$ \\ Carlos Eduardo Pinedo 2 \\ André PauloTschiptschin ${ }^{3}$
}

\section{Resumo}

Amostras de aço inoxidável UNSS31803 duplex foram nitretadas sob plasma em atmosfera gasosa de $75 \%$ de nitrogênio e $25 \%$ de hidrogênio em temperatura de $400^{\circ} \mathrm{C}$ durante 20 horas. A microestrutura do material como recebido apresentava cordões de ferrita e austenita, alinhados no sentido da laminação, com aproximadamente $50 \%$ de cada uma das fases. A caracterização microestrutural foi feita por microscopia óptica, difração de raios X, MEV e EBSD. As propriedades mecânicas e tribológicas das superfícies tratadas foram avaliadas utilizando ensaios de microdureza e esclerometria linear instrumentada. As camadas obtidas na nitretação a plasma em baixa temperatura (LTPN) eram constituídas por ferrita expandida $\left(\alpha_{N}\right)$ e austenita expandida $\left(\gamma_{N}\right)$, com durezas de $1509 \mathrm{HV}$ e de $1362 \mathrm{HV}$, respectivamente. Os ensaios de esclerometria linear mostraram que, num primeiro estágio, o indentador se movimenta sobre a camada nitretada, promovendo deformação plástica nas bordas do sulco, denotando a possibilidade de movimentação de discordância nas fases expandidas da camada nitretada. O coeficiente de atrito medido durante esse estágio ficou estável em torno de 0,05 . Ao final do primeiro estágio houve início de formação de microtrincas, aumentando o coeficiente de atrito aparente. A transição para o $2^{\circ}$ estágio ocorre com formação de microtrincas cuja densidade aumenta com o aumento da profundidade de risco. Nesse estágio o coeficiente de atrito cresce linearmente com o tempo e profundidade de risco, o número de microtrincas cresce e as microtrincas observadas são predominantemente transgranulares, típicas de falha coesiva da camada. Foram observadas, também, microtrincas intergranulares que causam o destacamento individual de pequenos grãos de ferrita e/ou austenita expandida. No terceiro estágio de riscamento o coeficiente de atrito aparente tende a se estabilizar em torno de 0,16 . O ensaio de esclerometria linear realizado no aço como recebido apresenta coeficiente de atrito sempre crescente até atingir um valor em torno de 0,21.

Palavras-chave: Aço Inoxidável Duplex, Nitretação sob Plasma, Austenita Expandida, Ferrita Expandida.

\section{EFFECT OF LOW TEMPERATURE PLASMA NITRIDING OF STEEL UNS $\$ 31803$ ON THE TRIBOLOGICAL PROPERTIES MESURED BY INSTRUMENTED SCRATSH TEST}

\section{Abstract}

Specimens of a UNS S31803 duplex stainless steel were plasma nitrided at $400^{\circ} \mathrm{C}$ by $20 \mathrm{~h}$, in a $75 \% \mathrm{~N}_{2}+25 \% \mathrm{H}_{2}$ atmosphere. The microstructure of the as received material is composed by ferrite and austenitic stringers, aligned in the roll direction. Light optical microscopy (LOM), scanning electron microscopy (SEM), X-ray diffraction (XRD) and electron-backscattered diffraction (EBSD) were used to characterize the microstructure. Microhardness and scratch tests were carried out in order to assess the surface properties. The plasma nitrided (LTPN) layer was composed by expanded ferrite $\left(\alpha_{N}\right)$ and expanded austenite $(\mathrm{YN})$, with microhardness of $1509 \mathrm{HV}$ and $1362 \mathrm{HV}$, respectively. Scratch tests showed that during the first stage of scratching, plastic deformation of the nitrided layer occurs at the border regions of the scratch, indicating dislocation movement in both expanded phases. The friction coefficient (COF) remained stable and was very small $\sim 0.05$. During the second stage small microcracks were observed, the amount of microcracks increasing with increasing depth of scratch. During this stage, the friction coefficient (COF) increases linearly with the depth of scratch, reaching a stable value $\sim 0.16$ at the third stage. The scratch test of the untreated specimens resulted in intense plastic deformation, no cracks were observed and the friction coefficient always increased reaching a stable value at the end of the test $\sim 21$.

Keywords: Duplex Stainless Steel, Plasma Nitrided, Expanded Austenite, Expanded Ferrite.

\footnotetext{
Estudante de Doutorado, Eng. Metalúrgica e de Materiais, Escola Politécnica, Universidade de São Paulo (EPUSP), São Paulo, SP, Brasil; luisvarelajimenez@usp.br.

2 Doutor em Ciências, Diretor Técnico, Heat-Tech Tecnologia em Tratamento Térmico e Engenharia de Superfície Ltda., Mogi das Cruzes, SP, Brasil; pinedo@heattech.com.br.

3 Professor Doutor, Depto. Eng. Metalúrgica e de Materiais, EPUSP, São Paulo, SP, Brasil; antschip@usp.br.
}

\footnotetext{
* Contribuição técnica ao $1^{\circ}$ Workshop de tratamentos de superfícies de ligas resistentes à corrosão,
} 21 a 25 de julho de 2014, São Paulo, SP, Brasil. 


\section{INTRODUÇÃO}

Os aços inoxidáveis duplex têm uma excelente resistência à corrosão, portanto, são materiais escolhidos para uma variada gama de aplicações, como componentes de reatores nucleares, componentes para a indústria química ou petroquímica [1]. No entanto, são caracterizados por sua baixa dureza e baixa resistência ao desgaste, o que tem impedido sua utilização em aplicações tribológicas e triboquímicas, sendo, portanto necessário um tratamento superficial que melhore as propriedades mecânicas e não diminua a resistência à corrosão.

O tratamento superficial de nitretação por plasma em baixa temperatura é aplicada em aços inoxidáveis para melhorar as suas propriedades superficiais, sem prejudicar a resistência à corrosão. O processo de nitretação em baixa temperatura de aços inoxidáveis ferríticos e duplex tem sido pouco estudado, tendo-se reportado na literatura resultados distintos em relação à formação das fases formadas durante a nitretação sob plasma neste tipo de aço. Blawert et al. [2] concluíram que a introdução do nitrogênio na superfície do aço austenítico-ferrítico promove a transformação da ferrita pré-existente em austenita expandida. Bielawski et al. [3, 4] encontraram que a formação de camadas enriquecidas com nitrogênio, depende da composição química da estrutura da matriz. Além disso, expuseram a dificuldade de estimar o caráter exato da camada formada nas regiões ferríticas da matriz e de chamá-la como "austenita expandida". Dong [5] mostrou a coexistência de grãos de austenita expandida e grãos ferríticos contendo nitrogênio, concluindo que a identificação de fase com base apenas em resultados de difração de raios-X não é confiável e pode ser às vezes enganosa. Chiu et al [6] reportou a formação de austenita expandida e ferrita expandida nos cordões das fases ferrita e austenita de um aço inoxidável duplex UNS S31803; utilizando a técnica EPMA fizeram medições do teor de nitrogênio, mostrando a ocorrência de altos níveis de supersaturação. Além disso, mostraram que o teor de nitrogênio encontrado na ferrita expandida foi maior do que na austenita expandida. Por outro lado, Bielawski [4], reportou teores menores de nitrogênio para a ferrita expandida do que para austenita expandida. Pinedo et al [7], indicaram a presença de austenita e ferrita expandida em um aço duplex AISI F51 por meio das técnicas de DRX e EBSD e, mostraram a presença de bandas de deformação na ferrita expandida enquanto que na austenita expandida só observaram bandas de deslizamento, devidas às tensões residuais de compressão existente na camada nitretada. Gontijo et al. [8] analisaram as camadas das fases de austenita expandida $\left(\mathrm{\gamma}_{\mathrm{N}}\right)$ e ferrita expandida $\left(\alpha_{\mathrm{N}}\right)$ formadas em amostras de aço austeníticos (CFC) e (CCC) ferríticos. Fazendo a deconvolução dos picos de difração para o aço ferrítico AISI 409 afirmam que é composta por três picos diferentes $\alpha_{N}^{1}(110), \alpha_{N}^{2}$ (200) e $\alpha(110)$ da ferrita da matriz. Com base nesta análise, concluiu que o estado de tensão causado pela presença do nitrogênio é maior na fase $\alpha_{N}$ comparado com a fase de $\gamma_{N}$.

O objetivo do trabalho é estudar a microestrutura da camada nitretada formada no aço duplex UNS S31803, em baixa temperatura, visando evitar a formação de nitretos de cromo que podem prejudicar a resistência à corrosão. Pretende-se, também, avaliar as propriedades tribológicas da camada obtida utilizando o ensaio de esclerometria linear instrumentada. Para este propósito as camadas formadas foram analisadas por meio de MEV, DRX, EBSD, microdureza e ensaio de esclerometria linear instrumentada.

* Contribuição técnica ao $1^{\circ}$ Workshop de tratamentos de superfícies de ligas resistentes à corrosão, 21 a 25 de julho de 2014, São Paulo, SP, Brasil. 


\section{MATERIAIS E MÉTODOS}

As amostras de aço UNS S310803 foram submetidas à nitretação sob plasma em baixa temperatura (LTPN) realizada em um reator a plasma da Plasma Metal SA Luxemburg, o qual dispõe de um sistema de tela ativa e fonte de tensão secundária nas amostras para a aplicação de "bias". O tratamento foi desenvolvido em atmosfera gasosa de $75 \%$ de nitrogênio e $25 \%$ de hidrogênio a uma temperatura de $400^{\circ} \mathrm{C}$ durante 20 horas e $400 \mathrm{~Pa}$ de pressão.

As fases formadas na camada nitretada foram avaliadas por difratometria de raios- $X$, por varredura contínua simples, método Bragg-Brentano $\theta-2 \theta$, com ângulo $2 \theta$ variando entre $20^{\circ}$ até $120^{\circ}$, passo de $0,02^{\circ}$, ao longo de 100 segundos, radiação Cu-Ka (KV/mA tubo: 40-40) em equipamento X'PERT.

Para a caracterização microestrutural, foram utilizados microscópio óptico Olympus, modelo BX60M e microscópio eletrônico de varredura Philips XL30TMP. Utilizou-se ataque eletroquímico com reagente Ácido Oxálico a 10\%. A dureza Vickers superficial foi medida diretamente sobre a superfície nitretada levemente polida, em microdurômetro Shimadzu HMV-2, usando cargas de $10 \mathrm{gf}$.

Os ensaios de esclerometria foram realizados de acordo com a norma ASTM C1624, em equipamento marca CETR - UMT Multi-Specimen Test System. O equipamento tem um indentador cônico de diamante tipo Rockwell, com ângulo de $120^{\circ}$ e raio de ponta de $200 \mu \mathrm{m}$. Em todos os ensaios, aplicou-se uma pré-carga de $-1 \mathrm{~N}$ durante 10 segundos. Em seguida o deslocamento do indentador foi feito com carga linearmente crescente com 0 tempo desde $-1 \mathrm{~N}$ até $-10 \mathrm{~N}$, velocidade de deslocamento de $0,1 \mathrm{~mm} / \mathrm{s}$ e tempo de ensaio de 60 segundos, obtendo-se um risco de $6 \mathrm{~mm}$ de comprimento. Durante os ensaios foram registrados, em função do tempo, a força normal, a força tangencial, o coeficiente de atrito e a emissão acústica. O critério empregado para determinar a ocorrência das falhas foi a análise visual do risco produzido.

Com base nos registros da força normal (Fz) aplicada e da força tangencial ( $F x)$ resultante, o equipamento calcula o coeficiente de atrito (COF) instantâneo no decorrer de todo o ensaio. Simultaneamente, um sensor de emissão acústica dedicado capta a emissão oriunda da interação entre a ponta de teste e o material. Essa emissão decorre de ondas elásticas geradas pela rápida liberação de energia durante a formação de trincas frágeis na camada nitretada. Outras variáveis monitoradas foram o tempo de ensaio (t), a profundidade $(Z)$ e o comprimento do risco $(\mathrm{X})$ produzido.

\section{RESULTADOS E DISCUSSÃO}

\subsection{Caracterização Microestrutural das Camadas Nitretadas}

A composição química do aço inoxidável duplex UNS S31803, conforme informada pelo fabricante do aço, é apresentada na Tabela 1.

Tabela 1. Composição química do aço UNS S31803. (\% em massa)

\begin{tabular}{cccccccc}
\hline $\mathbf{C}$ & $\mathbf{C r}$ & $\mathbf{N i}$ & $\mathbf{M o}$ & $\mathbf{N}$ & $\mathbf{S i}$ & $\mathbf{P}$ & $\mathbf{S}$ \\
\hline 0,016 & 22,60 & 4,30 & 3,06 & 0,20 & 0,66 & 0,009 & 0,001 \\
\hline
\end{tabular}

A microestrutura do aço duplex como recebido é apresentada na Figura 1. Observam-se cordões de austenita e ferrita, alinhados no sentido da laminação. $O$ tratamento de nitretação foi realizado na superfície normal à direção de laminação,

* Contribuição técnica ao $1^{\circ}$ Workshop de tratamentos de superfícies de ligas resistentes à corrosão, 21 a 25 de julho de 2014, São Paulo, SP, Brasil. 
com o intuito de analisar a formação da camada nitretada sobre os grãos de ferrita e austenita.

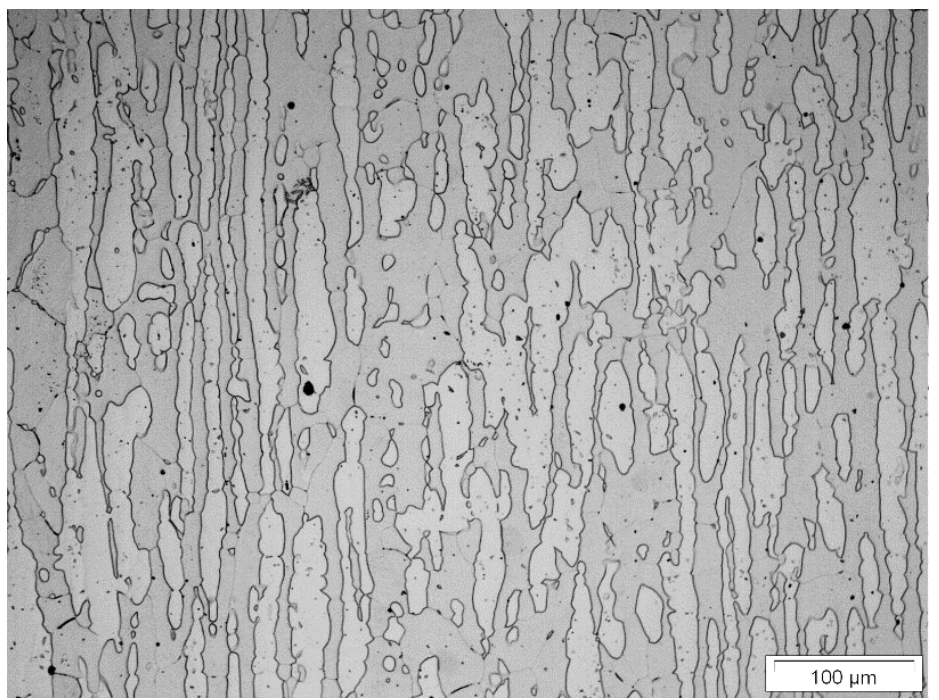

Figura 1. Microestrutura do aço UNS S31803 como recebido. MO

A Figura 2 mostra a superfície da amostra nitretada a plasma. A camada nitretada é contínua em toda a superfície (figura 2a), sendo formada pela difusão do nitrogênio tanto na ferrita como na austenita. A camada nitretada é menos espessa sobre os grãos de austenita do que sobre os grãos de ferrita, devido ao maior coeficiente de difusão do $\mathrm{N}$ na estrutura CCC. Na figura $2 \mathrm{~b}$, observa-se a morfologia da austenita expandida $(\sim 2,5 \mu \mathrm{m})$, cuja dureza é de $1362 \mathrm{HV} 0,01$ e da ferrita expandida $(\sim 3 \mu \mathrm{m})$, com dureza de 1509 HV 0,01. Ambas, austenita e ferrita expandida se encontram altamente deformadas, no entanto, na ferrita expandida, podem ser observadas bandas de deformação (figura $2 \mathrm{~b}$ ), formando ângulo de $45^{\circ} \mathrm{com}$ a superfície. As bandas de deformação são formadas devido à elevada tensão residual de compressão na camada nitretada decorrente da supersaturação do nitrogênio [7].

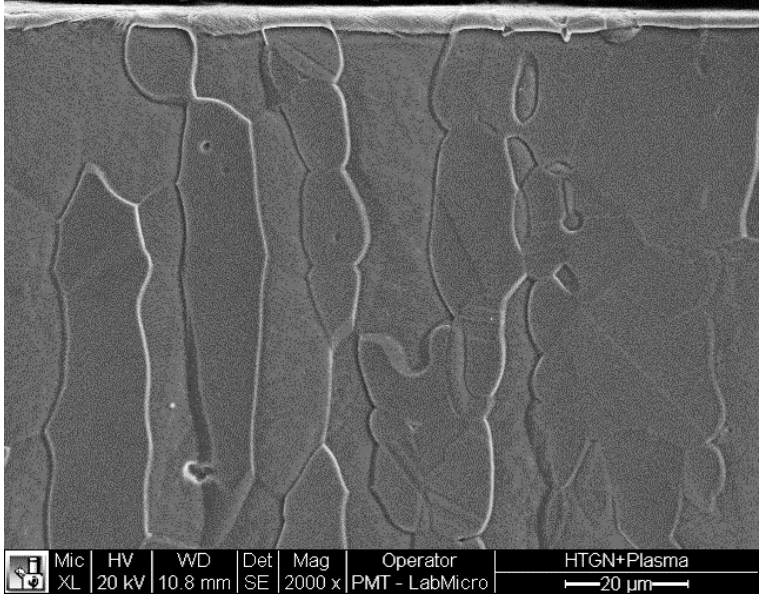

a)

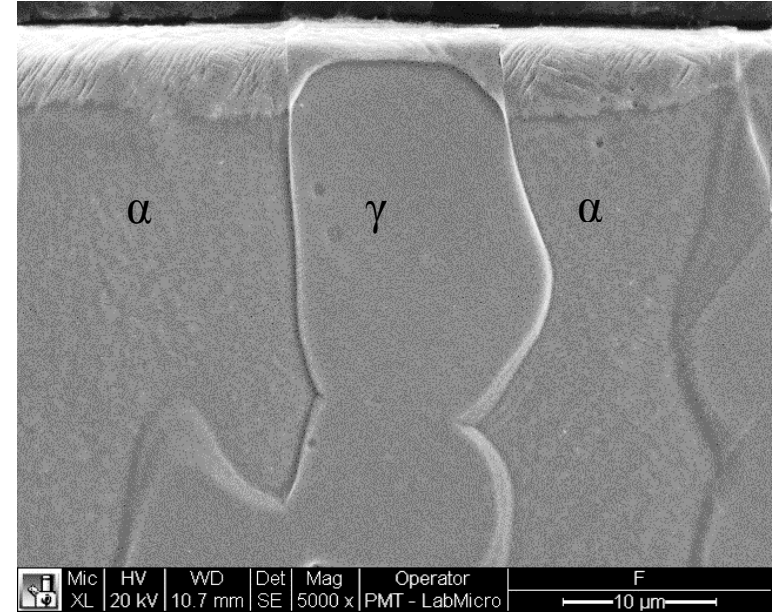

b)

Figura 2. Microestrutura do aço (LTPN) UNS S31803. a) $\alpha^{+}+\gamma$ no núcleo e camada de $\alpha_{N}+\gamma_{N}$ e b) detalhe da camada superficial $\alpha_{N}+\gamma_{N}$.

Dada a dificuldade de identificação das fases presentes resolveu-se analisar as camadas obtidas por mapeamento de orientações e identificação de fases utilizando a técnica de difração de elétrons retroespalhados.

* Contribuição técnica ao $1^{\circ}$ Workshop de tratamentos de superfícies de ligas resistentes à corrosão, 21 a 25 de julho de 2014, São Paulo, SP, Brasil. 


\subsection{Difração de Elétrons Retroespalhados (EBSD) e Identificação de Fases}

Os resultados de EBSD para amostra dúplex LTPN são apresentados na Figura 3. As regiões da camada nitretada formadas em cima dos grãos de austenita, foram indexadas como austenita, de acordo com resultados típicos apresentados na literatura [9] sobre a formação de austenita expandida de aços austeníticos nitretados em baixa temperatura. Embora a indexação das regiões da camada nitretada formadas em cima dos grãos de ferrita não tenham apresentado um bom índice de qualidade, há indicações de que essas regiões apresentam estrutura cúbica de corpo centrado, característica da ferrita. Além disso, não foram identificados nitretos de ferro e cromo nessa região. Observando detalhadamente a figura 3b, pode-se notar que o índice de confiança da indexação $(\mathrm{Cl})$ é menor, pois a região é bem mais escura na parte da camada formada na ferrita do que a formada na austenita, o que significa uma menor definição das linhas de Kikuchi e menor qualidade de indexação nestas regiões. Geralmente, a diferença em composição e tensões residuais grandes, pode diminuir a qualidade das linhas de Kikuchi [10]. Assim este efeito pode ser consequência do alto teor de nitrogênio nesta camada. Nas figuras $3 \mathrm{c}$ e $3 \mathrm{~d}$, são mostradas as regiões correspondentes à ferrita (CCC) e austenita (CFC), respectivamente.

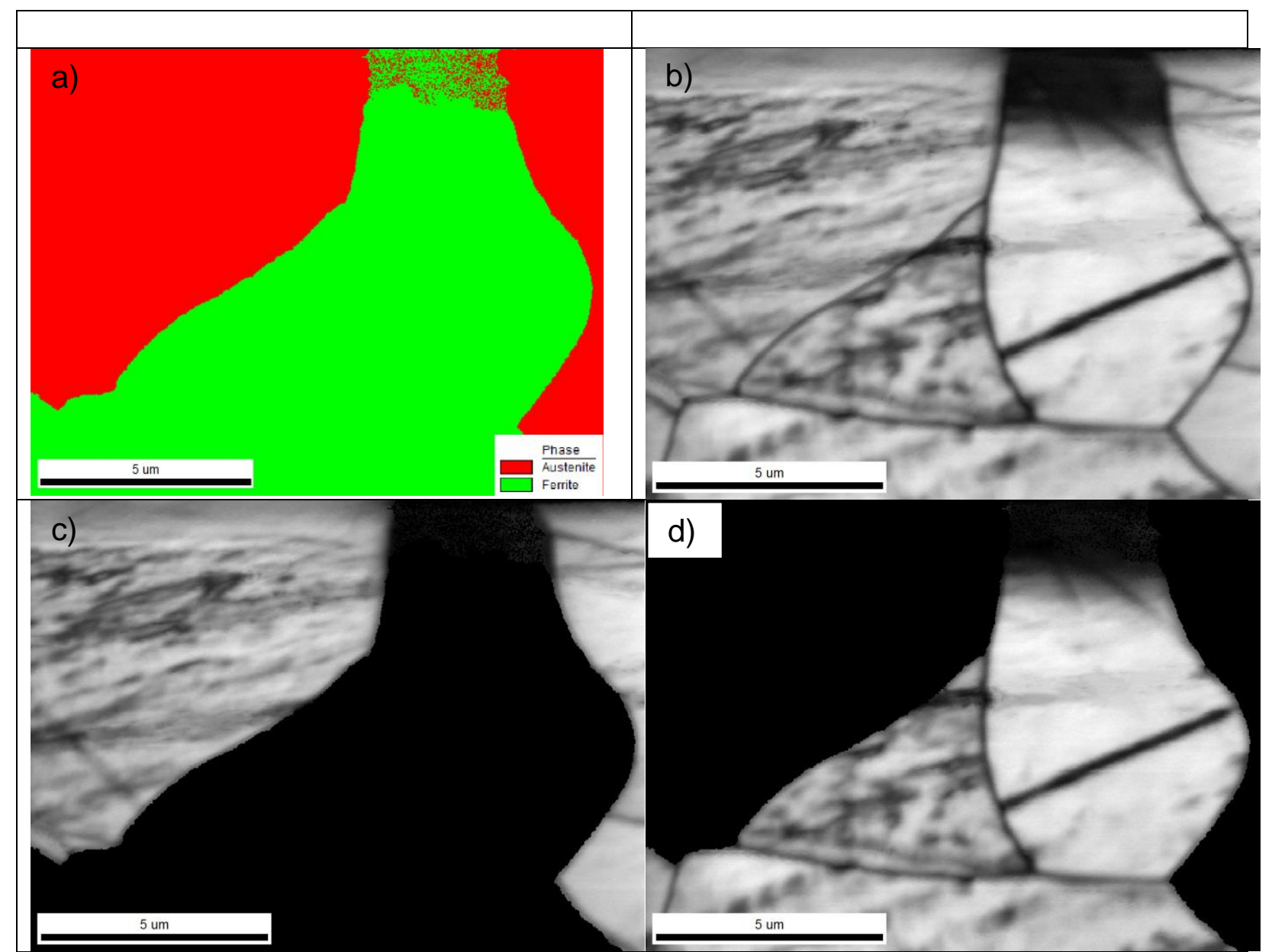

Figura 3. Resultados das medições por EBSD na ferrita-austenita da amostra LPTN UNS S31803 a) Mapa de identificação de fases, b) imagem de qualidade do EBSD, c) identificação da fase ferrítica e d) identificação da fase austenítica.

* Contribuição técnica ao $1^{\circ}$ Workshop de tratamentos de superfícies de ligas resistentes à corrosão, 21 a 25 de julho de 2014, São Paulo, SP, Brasil. 


\subsection{Difração de Raios-X}

A Figura 4 apresenta 0 resultado de difração de raios $X$ para a amostra UNS S31803. Pode-se observar a presença de picos de austenita e ferrita, indicando que a microestrutura é composta por duas fases.

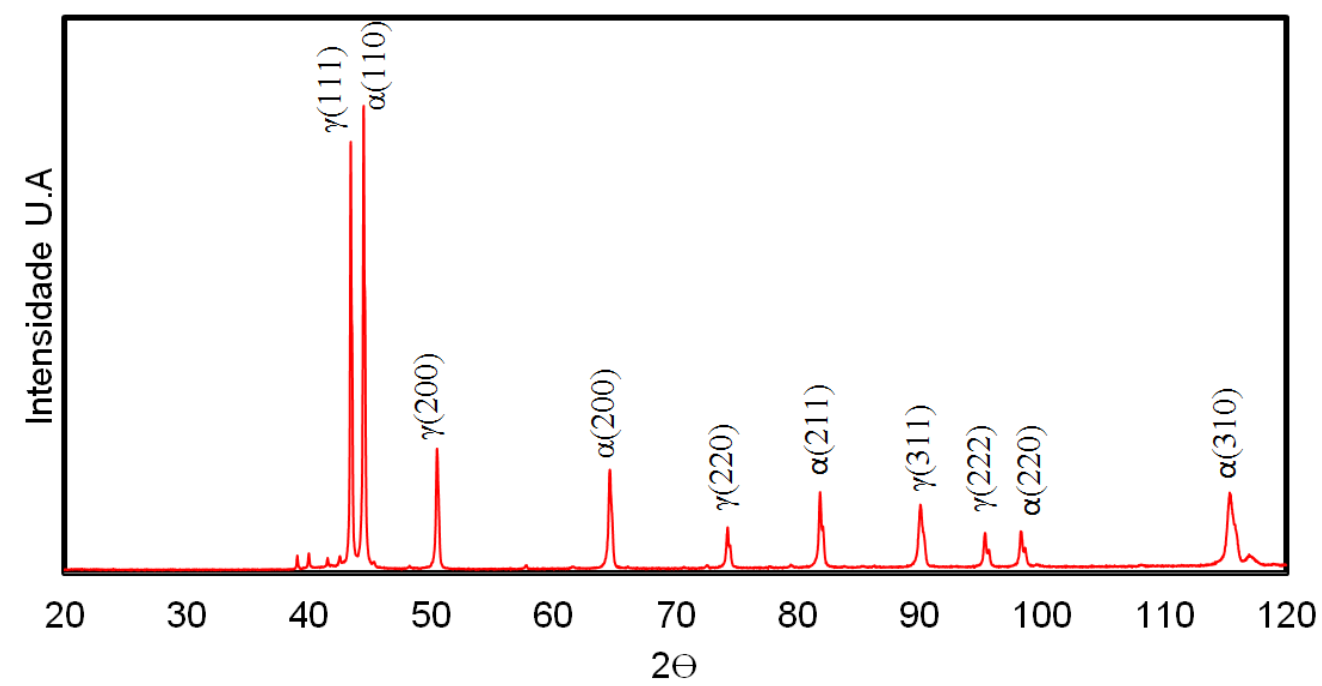

Figura 4. Difratograma do aço UNSS31808 como recebido

A Figura 5, apresenta difratograma da amostra UNS S31803 nitretada a plasma a $400^{\circ} \mathrm{C}$ (LTPN), onde foram identificadas as fases austenita expandida e ferrita expandida, bem como, as fases do substrato ferrita e austenita. Dois picos deslocados para a esquerda e alargados, apareceram em ângulos de difração $2 \theta=42,22^{\circ}$ e $2 \theta=48,21^{\circ}$, sendo identificados como austenita expandida, $\gamma_{\mathrm{N}}$, indicando um aumento nos parâmetros da rede cristalina devido à supersaturação do nitrogênio [18]. Além disso, os picos da ferrita $\alpha_{N}$ (110) e $\alpha_{N}(200)$, posicionados em ângulos $2 \theta$ de $44,48^{\circ}$ e $64,61^{\circ}$, se tornaram mais amplos e assimétricos, evidenciando a contribuição da ferrita expandida existente na camada nitretada.

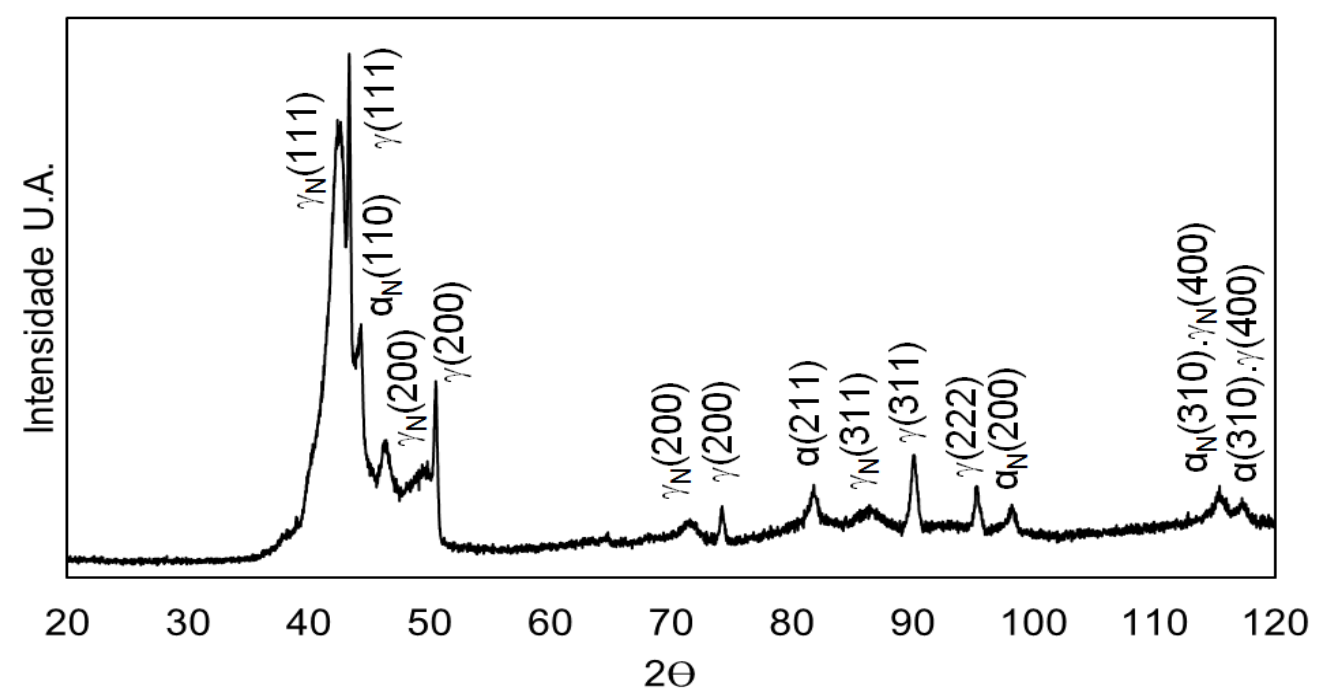

Figura 5. Difratograma do aço UNS S31803 LTPN indicando a presença da austenita expandida e ferrita expandida.

* Contribuição técnica ao $1^{\circ}$ Workshop de tratamentos de superfícies de ligas resistentes à corrosão, 21 a 25 de julho de 2014, São Paulo, SP, Brasil. 


\subsection{Esclerometria Linear Instrumentada}

A Figura 6 mostra a evolução do coeficiente de atrito ao longo do comprimento do risco, para a amostra UNS S31803 como recebido e para amostra UNS S31803 LTPN. Comparando a curva do coeficiente de atrito do aço UNS S31803 como recebido com a curva do aço UNS S31803 LTPN pode-se observar que:

1) o aço não nitretado apresenta coeficiente de atrito sempre crescente a partir de um valor relativamente alto 0,1 , chegando após $6 \mathrm{~mm}$ ao valor de 0,21

2) o aço nitretado a plasma em baixa temperatura apresenta, um primeiro estágio onde o coeficiente de atrito permanece estável e notavelmente baixo $\sim 0,05$, até a distância de $2 \mathrm{~mm}$. A partir dessa distância, um segundo estágio pode ser caracterizado, onde o coeficiente de atrito (COF) aumenta linearmente com a distância e profundidade do risco, até uma distância de $5 \mathrm{~mm}$. Um terceiro estágio ocorre a partir de $6 \mathrm{~mm}$ com aumento gradual até estabilização em uma distância de $6 \mathrm{~mm}$ e estabilização em valor $\sim 0,16$.

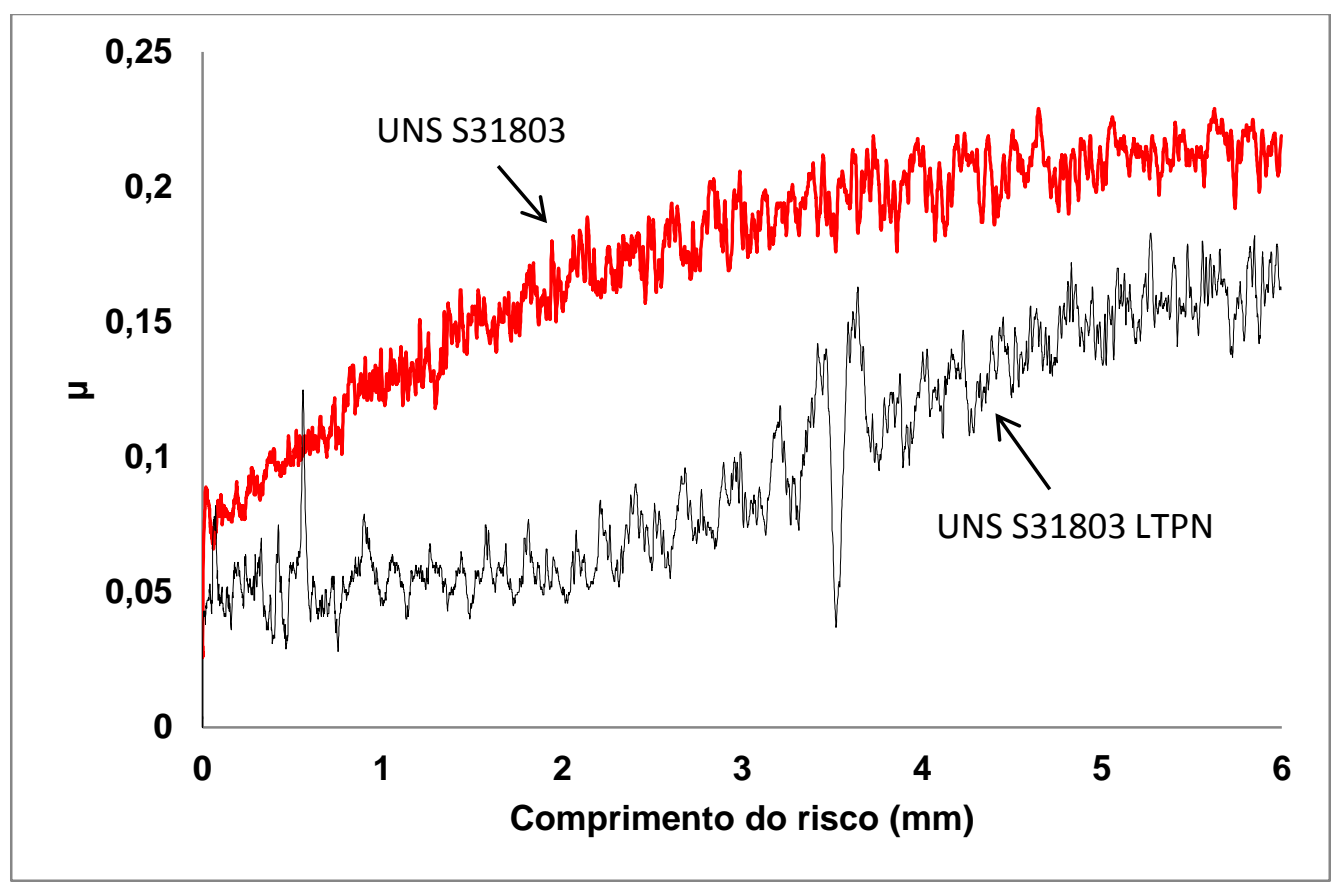

Figura 6. Coeficiente de atrito vs comprimento do risco, para as diferentes amostras.

Os sulcos gerados pela passagem do penetrador foram observados em microscópio eletrônico de varredura (MEV) visando identificar os mecanismos de falha e correlacioná-los com as variações de coeficiente de atrito observadas.

$\mathrm{Na}$ amostra nitretada foram observados três tipos de comportamento característicos, discutidos na Figura 9.

\subsubsection{Caracterização de danos observadas na trilha durante ensaio de esclerometria}

\subsubsection{Amostra como recebida}

$\mathrm{Na}$ Figura 7, observa-se a curva de variação do coeficiente de atrito vs. comprimento do risco, referente à amostra do material como recebido. Observa-se que o COF inicia com um valor relativamente baixo $\sim 0,1$, porém cresce continuamente com 0 aumento da carga normal. Nota-se que ao longo do microssulco feito pela passagem do penetrador não houve formação de trincas no material. Entretanto, foram

* Contribuição técnica ao $1^{\circ}$ Workshop de tratamentos de superfícies de ligas resistentes à corrosão, 21 a 25 de julho de 2014, São Paulo, SP, Brasil. 
detectados dois regimes diferentes: o primeiro, correspondente a um microssulcamento, onde o material deformado é somente deslocado para as laterais do risco. Com o aumento da carga, evidencia-se um segundo regime onde também ocorre microssulcamento, sendo observada a presença de material esmagado na trilha de desgaste, proveniente da proa formada pelo indentador, além de formação de bandas de cisalhamento nos grãos austeníticos. Durante o segundo regime de riscamento, observa-se também um aumento nas flutuações do sinal, possivelmente devido a instabilidades resultantes do contato do indentador com o material, causando o aumento do coeficiente de atrito, até alcançar um patamar $\sim 0,21$. Na Figura 8, observa-se intensa deformação plástica gerada nas laterais do microssulco, com presença de material esmagado e deslocado nas laterais.

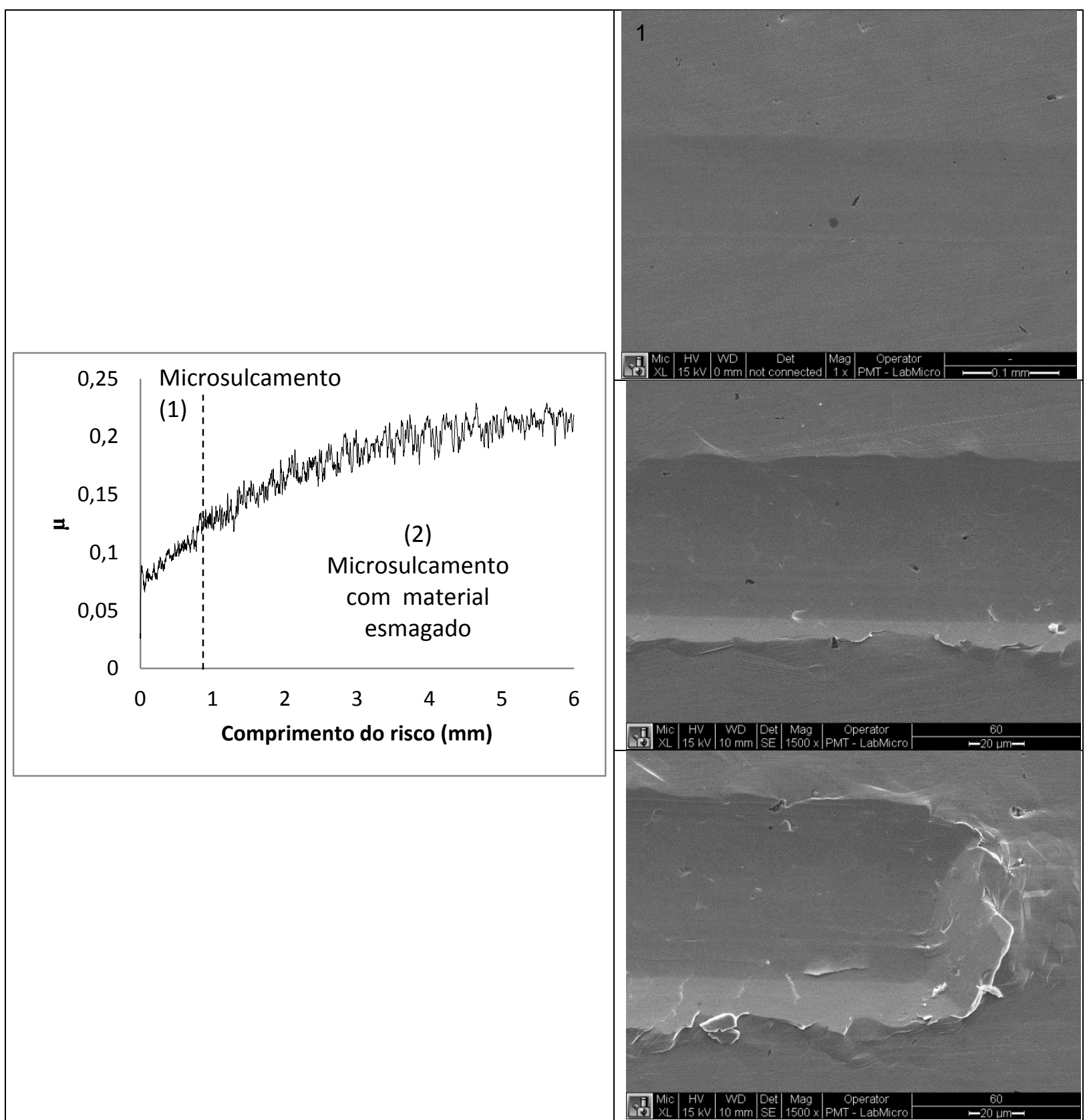

Figura 7. Resultados obtidos nos ensaios de esclerometria instrumentada (scratch test) realizados sobre a amostra UNS S31803 como recebido.

* Contribuição técnica ao 1 ํ Workshop de tratamentos de superfícies de ligas resistentes à corrosão, 21 a 25 de julho de 2014, São Paulo, SP, Brasil. 


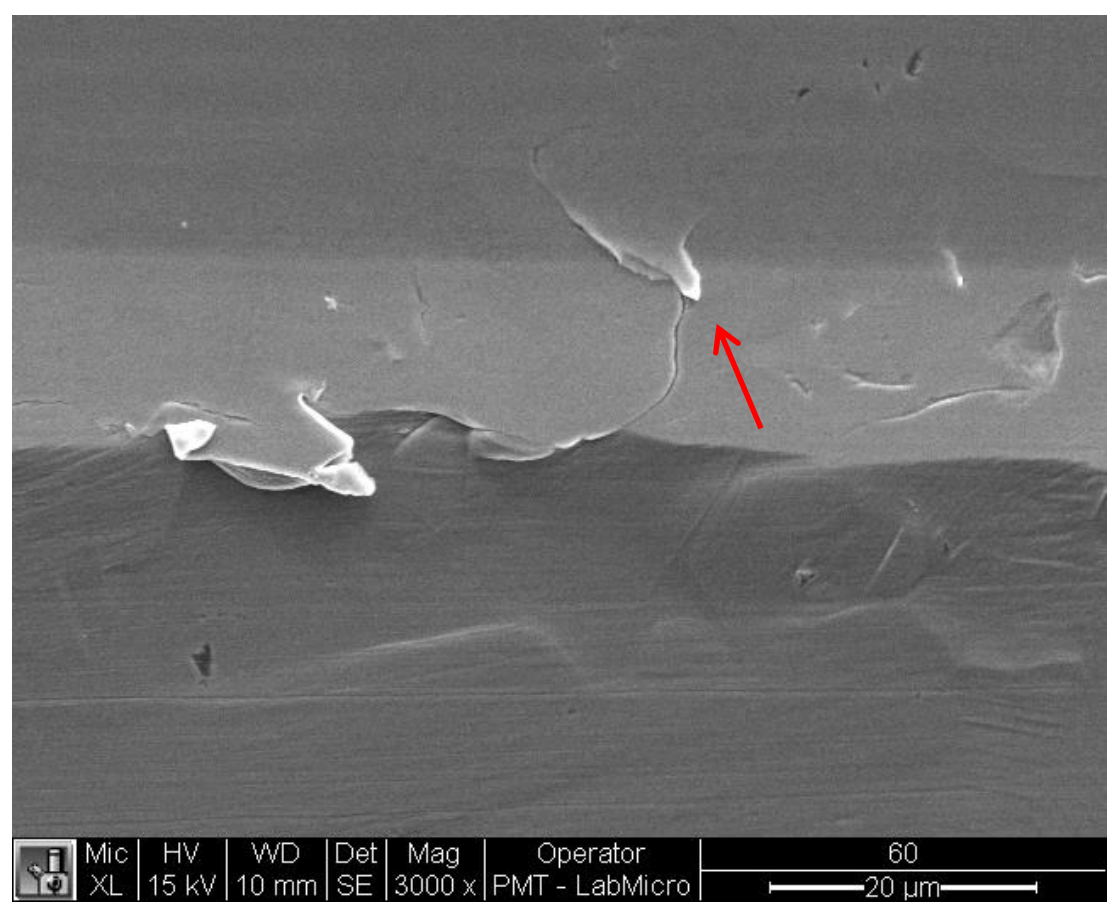

Figura 8. Detalhe de material esmagado na lateral na amostra LTPN UNS S3180331.

\subsubsection{Amostra nitretada a plasma}

A Figura 9 mostra a variação do coeficiente de atrito com a distância de riscamento. Observa-se que o coeficiente de atrito se mantém estável e muito baixo 0,05 até uma distância de $2 \mathrm{~mm}$. Nessa região observam-se somente bandas de cisalhamento nas bordas do sulco de riscamento. No final dessa região, com o aumento contínuo da carga aplicada começam a aparecer pequenas trincas na trilha de desgaste. Após $2 \mathrm{~mm}$ de riscamento o coeficiente de atrito aumenta linearmente com a profundidade do risco, até alcançar o valor $\sim 0,16$. Nessa região a densidade de trincas na trilha começa a aumentar, sendo que as trincas apresentam características típicas de "tensile crack". Segundo Bull [11], este tipo de dano aparece quando a dureza da camada é muito mais elevada do que a dureza do substrato. As trincas aparecem atrás da área de contato do indentador com a matriz. O aumento da carga causa aumento da densidade de trincas atrás do indentador.

* Contribuição técnica ao $1^{\circ}$ Workshop de tratamentos de superfícies de ligas resistentes à corrosão, 21 a 25 de julho de 2014, São Paulo, SP, Brasil. 


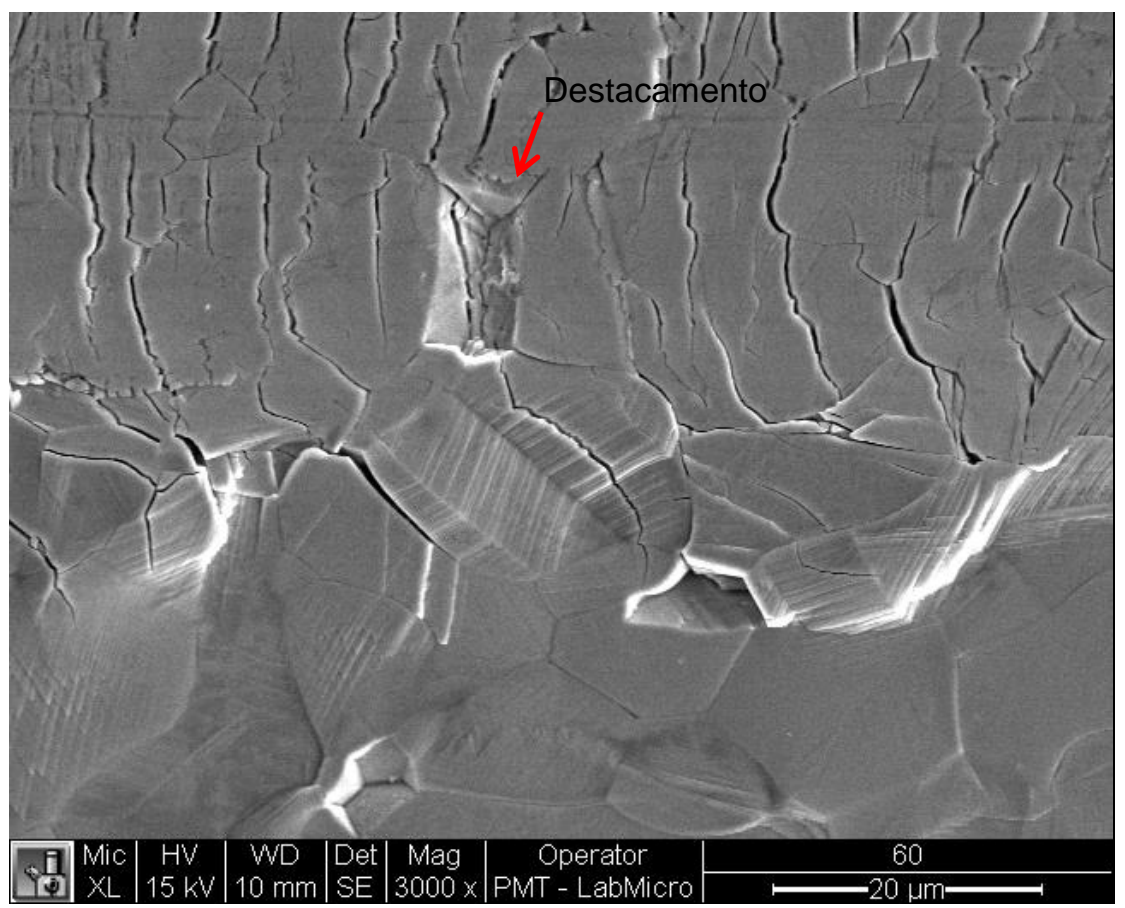

Figura 10. Detalhe da lateral na amostra LTPN UNS S3180331.

\section{CONCLUSÃO}

1) $\mathrm{O}$ aço duplex UNS $S 31803$ nitretado a plasma a $400^{\circ} \mathrm{C}$, apresentou uma camada nitretada composta por ferrita expandida e austenita expandida, com microdurezas de 1509 e $1362 \mathrm{HV} 0,01$, respectivamente.

2) O coeficiente de atrito entre a camada nitretada e o penetrador, ficou estável e significativamente baixo no início do ensaio $~ 0,05$, até uma distancia de $2 \mathrm{~mm}$. Nesse primeiro estágio foram observadas somente bandas de cisalhamento nas bordas do sulco de riscamento.

3) Um segundo estágio pôde se caracterizado, onde o coeficiente de atrito aparente aumenta linearmente com a profundidade de risco. Nesse estágio observa-se a presença de microtrincas do tipo "tensile crack" em sua maioria de caráter transgranular. Algumas microtrincas intergranulares, que provocam destacamento de grãos pouco profundos de austenita ou ferrita expandida presentes na camada nitretada, também puderam ser observadas.

4) O terceiro estágio de riscamento o coeficiente de atrito continua a aumentar até atingir um valor estável em torno de 0,16.

5) O aço UNS S31803 sem tratamento superficial, apresenta um comportamento do coeficiente de atrito sempre crescente a partir de $\sim 0,09$ até se estabilizar em um valor de $\sim 0,21$.

6) As microtrincas observadas caracterizam uma falha coesiva na camada, e se devem ao fato de a nitretação a plasma induzir gradientes de concentração de nitrogênio em solução sólida, produzindo uma camada de austenita expandida e ferrita expandida que pode ser considerada uma continuidade dos grãos de austenita e ferrita do substrato.

\section{Agradecimentos}

Os autores agradecem o apoio do CNPq pela concessão da bolsa de estudo do processo 151653/2010-0 e projeto CNPQ 481918/2010-8; à FAPESP pelo auxílio FAPESP - 2012/50890-0 de apoio ao convênio USP - University of Birmingham,

* Contribuição técnica ao $1^{\circ}$ Workshop de tratamentos de superfícies de ligas resistentes à corrosão, 21 a 25 de julho de 2014, São Paulo, SP, Brasil. 
Surface Engineering Research Group e à Villares Metals SA pela doação do material.

\section{REFERÊNCIAS}

1 Gunn RN. Duplex stainless steels: microstructure, propertiesand applications. Cambridge: Woodhead Publishing; 1997.

2 Blawert C, Mordike BL, Jirásková Y, et al. Structure and composition of expanded austenite produced by nitrogen plasma immersion ion implantation of stainless steels X6CrNiTi1810 and X2CrNiMoN2253. Surf Coat Tech. 1999;116-119:189-198.

3 Bielawski J, BaranowskaJ. Formation of nitrided layers on duplex steel -influence of ultiphase substrate Surf. Eng. 2010;26:299-304.

4 Bielawski J, Baranowska J. Microstructure and properties of layers on chromium steel Surf. Coat. Technol. 2006;200:6572-6577.

5 Dong $\mathrm{H}$. S-phase surface engineering of $\mathrm{Fe}-\mathrm{Cr}$, $\mathrm{Co}-\mathrm{Cr}$ and $\mathrm{Ni}-\mathrm{Cr}$ alloys, Int. Mater. Rev. 2010;55:65-98.

6 Chiu LH, Su YY, Chen FS. Microstructure and Properties of Active Screen Plasma Nitrided Duplex Stainless Steel Mater. Manuf. Process. 2010;25:316-323.

7 Pinedo CE; Varela L, Tschiptschin AP. Low-temperature plasma nitriding of AISI F51 duplex stainless steel. Surface \& Coatings Technology. 2013;232:839-843.

8 Gontijo LC, Machado R, Casteletti LC, Kuri SE, Nascente PAP. X-ray diffraction characterisation of expanded austenite and ferrite in plasma nitrided stainless steels, Surf. Eng. 2010;26(4):265-270.

9 Mesa DH, Pinedo CE, Tschiptschin AP. Improvement of the cavitation erosion resistence of UNS S31803 stainless steel by duplex treatment, Surface \& Coatings Technology. 2010;205(5):1552-1556.

10 Randal V, Engler O. Introduction to Texture Analysis, Macrotexture, Microtexture and Orientation Mapping. Singapure: Gordon and Breach Science Publisher; 2000.

11 Bull SJ. Failure mode map in the thin film scratch adhesion test. Tribology International. 1997;30:491-498.

* Contribuição técnica ao $1^{\circ}$ Workshop de tratamentos de superfícies de ligas resistentes à corrosão, 21 a 25 de julho de 2014, São Paulo, SP, Brasil. 